\title{
Analisi costo/efficacia di sevelamer nel trattamento dell'iperfosforemia del paziente in dialisi
}

\author{
Mario Eandi*, Nicola Giotta ${ }^{\circ}$, Gaia Santagostino Barbone\#
}

\begin{abstract}
Dialysis-associated hyperphosphatemia has been treated with chelating calcium salts, in particular with calcium carbonate. A new option for the management of this problem is represented by sevelamer, a chelating agent which contains no calcium and no metals. Sevelamer and calcium carbonate are more or less equally effective and tolerated. The prolonged use of sevelamer instead of calcium carbonate, nevertheless, reduces calcemia and $\mathrm{C}$-reactive protein levels, with a consequent reduction in myocardial infarction, angina pectoris and other peripheral vasculopathies. The limit to the wide-spread use of sevelamer is in its very high acquisition cost, as compared to the alternative. In this article, a semi-markovian pharmacoeconomical model for the comparison of clinical and economical outcomes of sevelamer and calcium carbonate is presented. The analysis is conducted in the perspective of the Italian health system (SSN). Clinical data are derived from published studies and integrated with expert panel estimates, cost data are relative to the Italian setting. The incremental cost-effectiveness analysis indicated that sevelamer is more costly, but also more costeffective: a one month gain in survival costs the SSN additional 2710 Euro, a value inferior to the conventionally accepted willingness-to-pay of industrialised countries. The majority of this excess cost is derived from the gain in survival, and consequent increase in dialysis costs. Thus, the choice of using sevelamer instead of calcium carbonate is even more justified from an ethical point of view. Sensibility analyses confirmed the robustness of the basic scenario results.
\end{abstract}

Farmeconomia e percorsi terapeutici 2004; 5 (4): 201-218

\section{INTRODUZIONE}

L'iperfosforemia dei pazienti con insufficienza renale cronica, dovuta alla ridotta escrezione renale di fosforo, è associata a gravi complicanze e all'aumento del rischio di mortalità [1-3]. Le principali complicanze consistono nell'iperparatiroidismo secondario, nell'osteodistrofia e nelle calcificazioni extraossee metastatiche [2].

Studi più recenti hanno dimostrato un'associazione tra elevato prodotto calcio-fosforo, livelli sierici elevati di fosforemia e aumento della mortalità nei pazienti dializzati [3]. Secondo l'ipotesi più accreditata, le alterazioni del metabolismo calcio-fosforo indurrebbero calcificazioni vascolari che coinvolgerebbero anche i vasi coronarici, responsabili di cardiopatia ischemica, infarto del miocardio, aritmie, arresto cardiaco e morte improvvisa [2-7]. Circa il 50\% delle cause di morte registrate nei pazienti in dialisi sono di origine cardiaca [8]. Diversi fattori, oltre al dismetabolismo del calcio-fosforo, sono stati correlati alla mortalità cardiaca del paziente in dialisi e tra questi i principali sono l'ipertensione arteriosa, l'intolleranza al glucosio, l'elevata concentrazione di omocisteina, la proteina C reattiva (PCR) e le dislipidemie [4, 9-13].

È stato dimostrato che la PCR ha valore predittivo della mortalità nei pazienti in trattamento sostitutivo dialitico. Wanner et al. hanno riportato che l'infiammazione cronica aumenta il rischio cardiovascolare e la mortalità ed Ikizler et al. hanno dimostrato l'importanza della PCR quale elemento indipendente che determina l'ospedalizzazione dei pazienti in dialisi $[14,15]$.

Considerando che la PCR è un marker di rischio cardiovascolare e che l'iperfosforemia e l'elevato prodotto calcio-fosforo sono associati ad aumento del rischio di morte, si può ipotizzare una relazione diretta tra PCR e calcificazioni cardiovascolari [16].

La presenza di dislipidemia nel paziente dializzato può contribuire ad aumentare il ri- 
schio di aterosclerosi delle coronarie e di altri distretti vascolari periferici $[13,17]$. Tuttavia non è chiaro se la condizione di uremia cronica modifichi, peggiorandola, la correlazione tra livelli di lipidi e rischio di morbilità e di mortalità della popolazione in generale $[18,19]$. Recentemente è stata avanzata l'ipotesi che nei pazienti uremici cronici sarebbero deficitarie alcune proteine regolatrici del metabolismo calcico quali la fetuina (alpha 2-Heremans Schmid glycoprotein) e la MGP (matrix Gla protein) e tale deficit predisporrebbe questi pazienti alle calcificazioni extraossee [20].

L'iperfosforemia del paziente in dialisi può essere controllata solo parzialmente riducendo l'introito dietetico di fosforo. Ogni seduta dialitica rimuove circa $800 \mathrm{mg}$ di fosforo ma è praticamente impossibile ridurre l'apporto dietetico di fosforo a meno di $1000 \mathrm{mg}$ al giorno, dovendo provvedere ad un apporto proteico giornaliero di almeno $1-1,2 \mathrm{~g} / \mathrm{kg}$ [21]. Pertanto la maggior parte dei pazienti dializzati, ben nutriti, presenta un bilancio positivo del fosforo e circa il $90 \%$ dovrebbe utilizzare leganti del fosforo per ridurre l'assorbimento del fosforo alimentare e mantenere la fosforemia entro livelli di sicurezza [22-24].

L'idrossido di alluminio è stato il primo legante introdotto in terapia per ridurre l'assorbimento di fosforo alimentare e controllarne l'accumulo. L'alluminio è un efficace legante del fosforo che funziona a tutti i livelli di $\mathrm{pH} \mathrm{e}$ può essere facilmente gestito dallo stesso paziente, ma il rischio di intossicazioni acute (encefalopatie e patologie del sistema nervoso centrale) e croniche (osteomalacia, miopatie, epatopatia, anemia) ne hanno consigliato l'abbandono a favore dei leganti a base di calcio [22, 23].

I principali sali di calcio utilizzati come leganti del fosforo sono: il carbonato, l' acetato e l' $\alpha$-chetoglutarato. In Italia, il più utilizzato nella pratica clinica è il calcio carbonato, che è stato anche il primo sale di calcio introdotto in terapia come legante del fosforo. Il carbonato di calcio è efficace nel ridurre i livelli sierici di fosforo ed è disponibile in commercio in diverse formulazioni, tutte a basso prezzo, ma con differente biodisponibilità. La solubilità e l'azione legante del carbonato di calcio è $\mathrm{pH}$-dipendente e richiede un ambiente acido come condizione ottimale. Diversi fattori biofarmaceutici (tipo di formulazione) e clinici (secrezione gastrica, uso di farmaci antiacidi, bassa compliance) possono ridurre l'efficacia del carbonato di calcio e comportare un insoddisfacente controllo dell'iperfosforemia [22-24].

I pazienti in dialisi trattati con sali di calcio come leganti del fosforo tendono ad avere un bilancio positivo del calcio e a depositarne il surplus in diversi tessuti dell' organismo: cuore, arterie, cute, polmoni, tratto gastrointestinale e reni [25-29].

È opinione consolidata che l'elevata frequenza di calcificazioni vascolari derivanti dall'utilizzo di questi farmaci contribuisca all'elevato tasso di mortalità cardiovascolare osservato nei pazienti dializzati. Infatti, in tali pazienti gli unici fattori di rischio modificabili sono rappresentati dai livelli sierici di fosforo e dall'intake di calcio: peraltro le calcificazioni cardiovascolari compaiono in tempi brevi e il loro sviluppo è già evidente dopo sei mesi di terapia.

Come alternativa ai sali di calcio sono stati sviluppati o sono in sviluppo altri farmaci capaci di legare il fosforo, ma privi sia di calcio che di metalli. Il sevelamer cloridrato (Renagel囚) è l'alternativa più valida ai sali di calcio attualmente disponibile in commercio. È costituito da un polimero specificamente sviluppato per chelare il fosforo, ma dotato di una qualche capacità chelante anche nei confronti di altre sostanze endogene ed esogene, ed in particolare degli acidi biliari [30].

L'efficacia di sevelamer sul controllo della fosforemia è equivalente a quella dei sali di calcio [30-33]. A differenza del calcio, però, l'uso di sevelamer comporta minori livelli di calcemia, la riduzione dei livelli di PCR, il rallentamento della progressione delle calcificazioni vascolari, una minore incidenza di infarto del miocardio, di angina pectoris e di altre vasculopatie periferiche [34-36].

L'uso cronico di sevelamer, oltre a normalizzare i livelli di fosforo sierico, di ormone paratiroideo e di calcio nella maggior parte dei pazienti che hanno una buona compliance, comporta anche una significativa riduzione dei livelli di LDL-colesterolo, talvolta accompagnato da un incremento dei livelli di HDL [37-39]. Questo risultato può contribuire alla riduzione del rischio cardiovascolare e ad aumentare la sopravvivenza dei pazienti in dialisi. Inoltre, la riduzione del colesterolo comporta anche la riduzione della percentuale di pazienti che devono essere trattati con una statina [35].

In effetti, questi risultati sul metabolismo del calcio-fosforo, sul metabolismo lipidico e sulla calcificazione dei tessuti sono stati correlati ad una riduzione dei casi di ricovero ospedaliero, soprattutto per complicanze cardiovascolari, ed anche alla riduzione della mortalità cardiovascolare dei pazienti dializzati $[40,41]$. Sevelamer può essere usato in associazione con leganti a base di calcio al fine di migliorarne il risultato terapeutico nei soggetti che non rispondono in modo soddisfacente [42, 43]. Sevelamer non interferisce sulla biodisponibilità della digossina e della warfarina spesso utilizzati in questi pazienti [44]. 
La tollerabilità gastrointestinale di sevelamer è equivalente a quella dei preparati a base di calcio.

Il principale inconveniente di sevelamer consiste nel prezzo elevato, fattore che attualmente ne riduce l'impiego e la diffusione. Tuttavia, i vantaggi di sevelamer nei confronti dei sali di calcio evidenziati negli studi clinici, come riduzione delle complicanze e della mortalità associate alla dialisi, potrebbero giustificare il maggior costo del prodotto.

In questo lavoro intendiamo affrontare questo tema, valutando con un apposito modello decisionale la costo/efficacia di sevelamer, in confronto con il calcio carbonato, e assumendo la prospettiva del Sistema Sanitario Nazionale (SSN) italiano.

\section{METODO}

\section{Modello decisionale}

L'analisi costo/efficacia (CEA) è stata attuata mediante il modello decisionale semimarkoviano, rappresentato nella figura 1. Alla radice dell' albero decisionale viene rappresentato il problema della scelta tra calcio carbonato e sevelamer (Renagel@) nel trattamento dell'iperfosforemia dei pazienti in dialisi (RRT). Ciascuna delle due diramazioni basali dell'albero continua in un'identica struttura markoviana, mediante la quale viene rappresentata l'evoluzione nel tempo degli stati di salute-malattia in cui si viene a trovare la popolazione dei pazienti analizzata.

I modelli di Markov elencano un insieme di stati, mutuamente esclusivi, nei quali un membro della coorte di pazienti può trovarsi come condizione di partenza o come risultato di processi di transizione in ognuno dei cicli temporali successivi. Un insieme di probabilità iniziali determina la distribuzione dei membri della coorte tra i possibili stati all'inizio del processo. Una matrice di probabilità di transizione viene quindi applicata in ogni ciclo successivo, di uguale intervallo temporale, per determinare le transizioni possibili da ogni stato di Markov, ossia per rappresentare le modificazioni nello stato di salute. La permanenza in ognuno degli stati previsti dal modello comporta un consumo di risorse specifico e il guadagno di uno specifico beneficio (ad esempio un periodo di sopravvivenza pari alla durata del ciclo, oppure un periodo di sopravvivenza ad un dato livello di qualità di vita). La transizione da uno stato all'altro può comportare consumo di risorse, come nel caso di un ricovero per complicanze in corso di dialisi. Per ogni ciclo successivo, compreso quello finale, è quindi possibile stimare un rapporto costo/efficacia. I modelli di Markov posso- no rappresentare l'evoluzione delle condizioni di salute della coorte di pazienti per un numero di cicli più o meno elevato in funzione dell'interesse del decisore a proiettare in un arco temporale più o meno lungo la sua valutazione.

La struttura markoviana utilizzata nel nostro modello prevede 6 differenti stati, mutuamente esclusivi, nei quali il paziente può trovarsi (figura 1A): emodialisiemodiafiltrazione (HD), complicanza in corso di emodialisi (HDc), dialisi peritoneale (PD), complicanza in corso di dialisi peritoneale (PDc), trapianto (TX), deceduto (D). Lo stato di deceduto è "assorbente", cioè senza ritorno. Da ognuno degli altri 5 stati sono possibili transizioni diverse, eventualmente con passaggi intermedi, verso ciascuno degli stati markoviani. Nel nostro modello abbiamo previsto le transizioni rappresentate nella figura 1 , riquadri $\mathrm{B}, \mathrm{C}$ e D. Il passaggio al trapianto può avvenire solo dallo stato $\mathrm{HD}$ o $\mathrm{PD}$. La morte può avvenire da ognuno dei rimanenti 5 stati. Dallo stato HD, coloro che non vengono trapiantati e che non muoiono, possono permanere nello stato nel ciclo successivo oppure andare incontro ad una delle complicazioni previste dal modello (figura 1B). Una struttura analoga è prevista per coloro che si trovano nello stato PD (figura 1C). Dallo stato HDc o PDc, coloro che sopravvivono possono ritornare alle condizioni HD o PD omologhe oppure cambiare tecnica di dialisi. Coloro che sono stati trapiantati possono solo transitare nel proprio stato (sopravvivere) oppure morire (figura 1D). Per non complicare inutilmente il modello non abbiamo considerato i pur possibili ritorni alla dialisi da parte di soggetti trapiantati che rigettano l'organo trapiantato in maniera acuta o cronica.

La durata del ciclo nel presente modello è stata fissata in un mese. In accordo con altri autori, abbiamo assunto che la permanenza in uno stato di complicazione mediamente non sia superiore al tempo di un ciclo (1 mese) [45].

Ai fini dell' effettuazione dell' analisi costo/ efficacia, il modello è stato rifornito dei necessari parametri di probabilità, di costo e di efficacia relativi alle due alternative confrontate, sevelamer vs calcio carbonato.

\section{Prospettiva}

L'analisi decisionale è stata effettuata assumendo come prospettiva quella del SSN italiano, che, secondo l'attuale sistema di Stato Sociale, ha l'onere di provvedere integralmente all'assistenza sanitaria dei pazienti con insufficienza renale cronica che necessitano di dialisi (100\% di invalidità civile).

Pertanto i parametri di probabilità e di costo assunti nel modello sono riferiti, per quan- 
to di pertinenza, alle condizioni assistenziali italiane nell' anno 2003 o di quelli immediatamente precedenti.

\section{Parametri di probabilità}

Il modello proposto assume che le coorti di pazienti trattati rispettivamente con sevelamer e con calcio carbonato presentino la medesima distribuzione nei 6 stati del modello di Markov. Inoltre, abbiamo assunto che tutti i soggetti di entrambi le coorti inizialmente siano ripartiti esclusivamente tra lo stato HD e lo stato PD. Ciò consente di valutare con maggior precisione e chiarezza le conse-

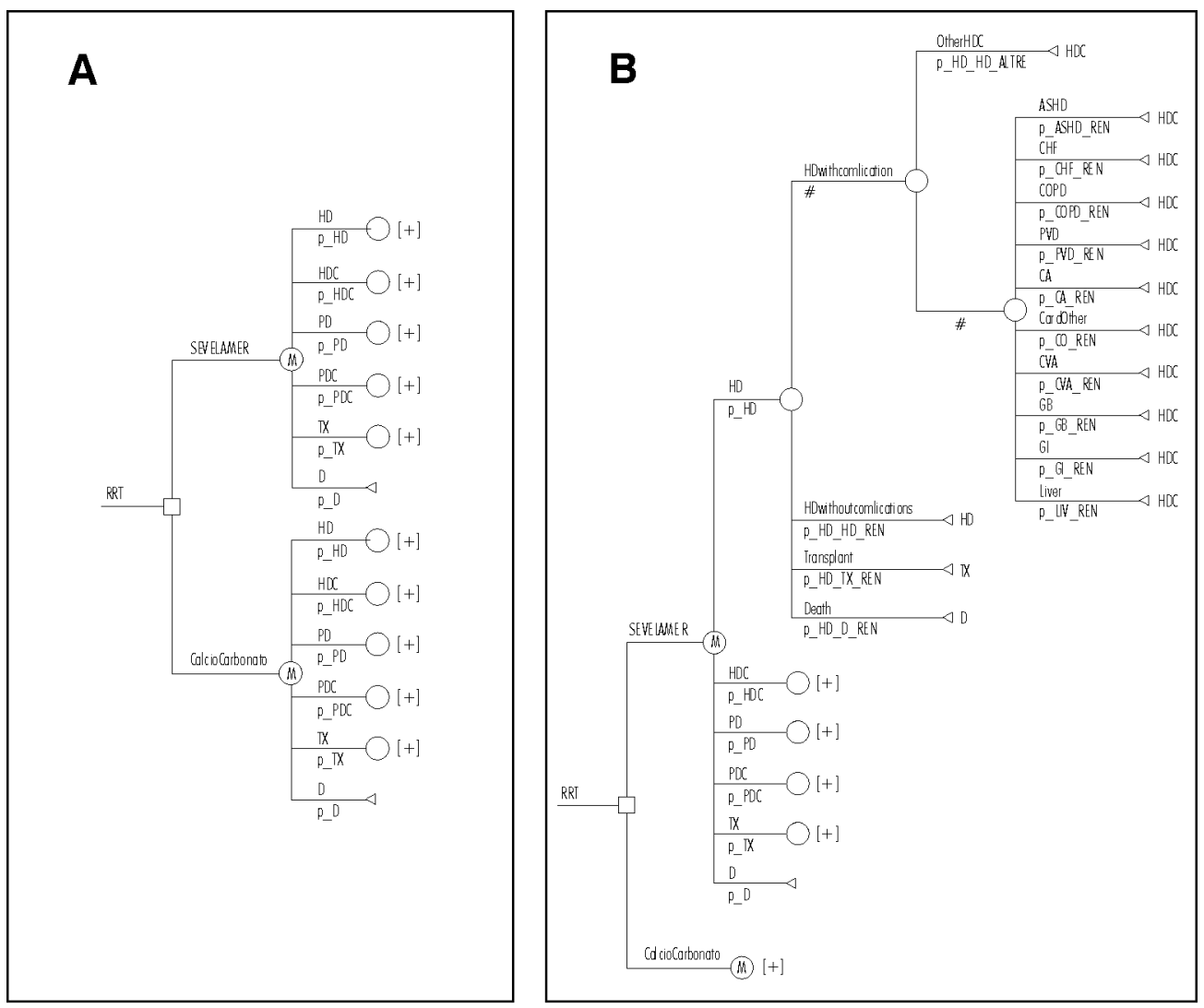

Figura 1

Struttura del modello decisionale semimarkoviano

Legenda

HD: emodialisi 0 emodiafiltrazione; HDc: complicazione in corso di emodialisi o emodiafiltrazione; PD: dialisi peritoneale; PDc: complicazione in corso di dialisi peritoneale;

TX: trapianto renale; D: morte.

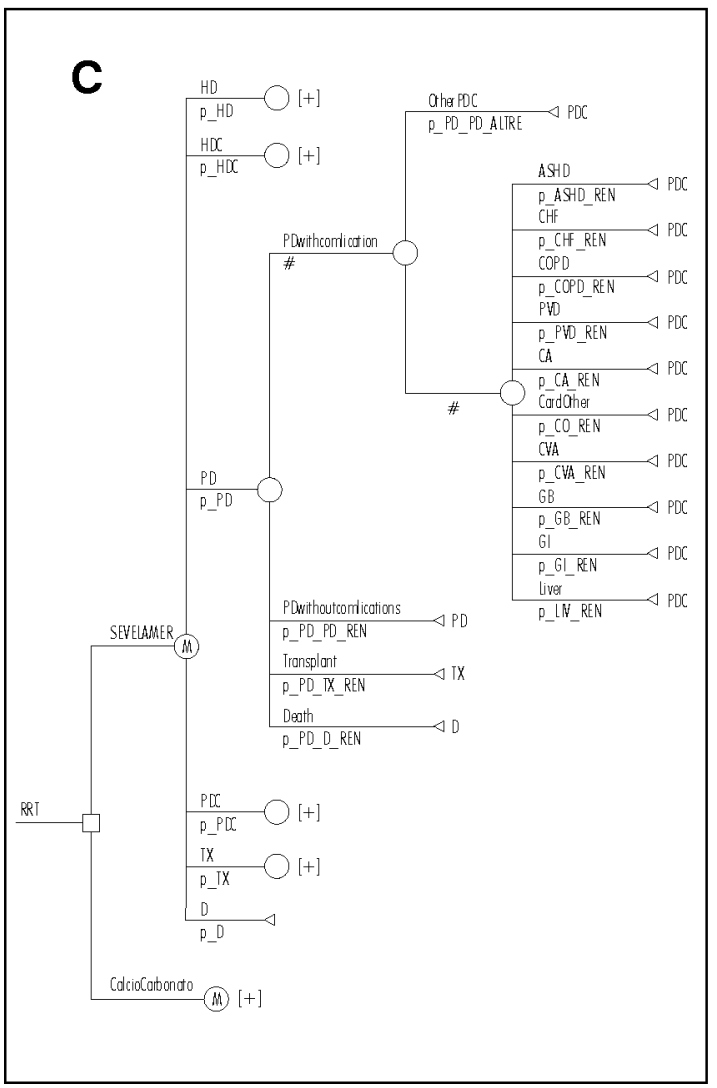

D

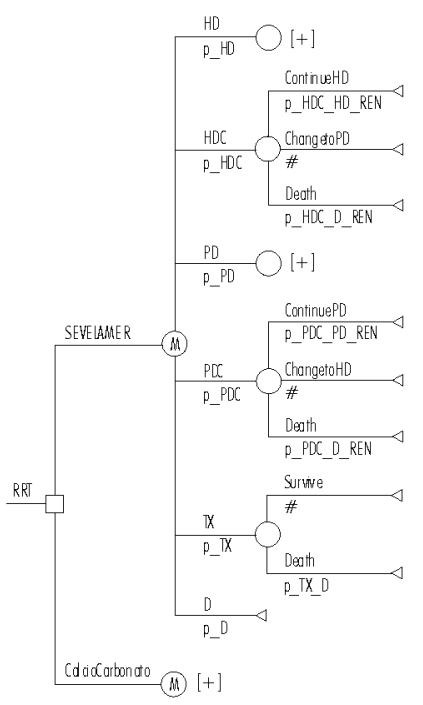


guenze differenziali dei due trattamenti. Le probabilità di trovarsi inizialmente nello stato HD e PD sono state desunte dal Registro Italiano dei Pazienti in Dialisi gestito dalla Società Italiana di Nefrologia (SIN). Negli ultimi anni poco meno del $90 \%$ dei soggetti in dialisi in Italia sono trattati con emodialisi o emodiafiltrazione. Nel modello abbiamo assunto che inizialmente il $12,5 \%$ sia trattato con dialisi peritoneale e l'87,5\% con emodialisi o emodiafiltrazione.

I parametri di transizione tra stati del modello markoviano sono stati ricavati dal lavoro di Kirby e Vale, integrandoli con i parametri di transizione verso il trapianto da noi stimati in base ai dati del Registro Italiano Trapianti [45].

Nella tabella 1 sono riportate le probabilità dello stato iniziale e le probabilità di transizione tra stati previsti dal modello nel caso in cui la coorte sia trattata con calcio carbonato (terapia di riferimento). I parametri di transizione relativi alla coorte trattata con sevelamer sono stati opportunamente modificati per rappresentare l'efficacia aggiuntiva di questo farmaco, rispetto ai sali di calcio, in termini di riduzione delle complicanze e della mortalità associate alla dialisi.

Dal lavoro di Collins e collaboratori abbiamo ricavato che l'uso di sevelamer, rispetto ai sali di calcio, comporta una riduzione significativa di oltre il $50 \%$ del rischio di prima ospedalizzazione per complicanze e una riduzione tendenzialmente significativa della mortalità di oltre il 40\% [41].

Per lo scenario base del modello abbiamo assunto che la somministrazione di sevelamer, rispetto al calcio carbonato, comporti un rischio relativo (RR) di complicazioni in corso di HD e PD di 0,46 e un rischio relativo di mortalità in corso di dialisi di 0,56. Pertanto, nella coorte di pazienti trattati con sevelamer le probabilità di transizione verso le complica- zioni HDc e PDc e verso la morte sono state corrette in base a tali valori di rischio relativo, e il vantaggio acquisito è stato attribuito esclusivamente alla probabilità di permanere negli stati HD e PD.

Lo studio caso-controllo di Collins e collaboratori ha dimostrato che l'incidenza di primo ricovero per complicanze in corso di emodialisi è significativamente ridotta con sevelamer, rispetto ai sali di calcio, considerando sia l'intera coorte dei pazienti sia i sottogruppi omogenei per tipo di complicazione. Inoltre, il rischio di singole complicazioni e la riduzione di tale rischio correlata all'uso di sevelamer variano sensibilmente in relazione al tipo di complicazione considerata (figura 2) [41].

Abbiamo tenuto conto di questa evidenza nell'implementazione del nostro modello e dalle incidenze riportate nella figura 2 abbiamo ricavato le probabilità di transizione verso le singole 10 principali complicazioni che hanno dimostrato un'incidenza differenziale tra sevelamer e calcio carbonato (vedi figura $1 \mathrm{~B} \mathrm{e}$ 1C). Le 10 complicazioni considerate non esauriscono la totalità delle complicazioni possibili in corso di emodialisi o di dialisi peritoneale. Abbiamo tenuto conto di ciò, assumendo nel modello che durante il primo anno le 10 complicazioni esplicitate rappresentassero la metà delle complicazioni, mentre negli anni successivi rappresentassero il 95\% delle complicazioni da emodialisi e il $90 \%$ delle complicazioni da dialisi peritoneale.

La probabilità di essere trattati con una statina è stata ricavata dallo studio di Chertow e collaboratori: nella coorte sevelamer tale probabilità è del $22 \%$, mentre nella coorte del calcio è del $46 \%$ [35]. Tale differenza è in relazione all'efficacia di sevelamer nel ridurre i livelli di LDL-colesterolo.

Probabilità di transizione verso lo stato al termine di ciascun ciclo

\begin{tabular}{|c|c|c|c|c|c|c|c|c|}
\hline \multirow[t]{2}{*}{$\begin{array}{r}\text { Stato di } \\
\text { partenza }\end{array}$} & \multirow[t]{2}{*}{$\begin{array}{r}\text { Probabilità iniziale } \\
\text { di essere nello stato }\end{array}$} & \multicolumn{7}{|c|}{$\begin{array}{l}\text { Probabilità di transizione verso lo stato } \\
\text { al termine di ciascun ciclo }\end{array}$} \\
\hline & & $\begin{array}{r}\text { Ciclo } \\
\text { (mese) }\end{array}$ & TX & HD & HDc & PD & PDc & D \\
\hline $\mathrm{HD}$ & 0,875 & $\begin{array}{r}0-12 \\
13-120\end{array}$ & $\begin{array}{l}0,0025 \\
0,0025\end{array}$ & $\begin{array}{l}0,9225 \\
0,9795\end{array}$ & $\begin{array}{r}0,06 \\
0,003\end{array}$ & $\begin{array}{l}0 \\
0\end{array}$ & $\begin{array}{l}0 \\
0\end{array}$ & $\begin{array}{l}0,015 \\
0,015\end{array}$ \\
\hline HDc & 0 & $\begin{array}{r}0-12 \\
13-120\end{array}$ & $\begin{array}{l}0 \\
0\end{array}$ & $\begin{array}{r}0,961 \\
0,98\end{array}$ & $\begin{array}{l}0 \\
0\end{array}$ & $\begin{array}{l}0,024 \\
0,005\end{array}$ & $\begin{array}{l}0 \\
0\end{array}$ & $\begin{array}{l}0,015 \\
0,015\end{array}$ \\
\hline PD & 0,125 & $\begin{array}{r}0-12 \\
13-120\end{array}$ & $\begin{array}{l}0,0025 \\
0,0025\end{array}$ & $\begin{array}{l}0 \\
0\end{array}$ & $\begin{array}{l}0 \\
0\end{array}$ & $\begin{array}{l}0,7555 \\
0,9655\end{array}$ & $\begin{array}{l}0,228 \\
0,017\end{array}$ & $\begin{array}{l}0,014 \\
0,015\end{array}$ \\
\hline PDc & 0 & $\begin{array}{r}0-12 \\
13-120\end{array}$ & $\begin{array}{l}0 \\
0\end{array}$ & $\begin{array}{l}0,024 \\
0,015\end{array}$ & $\begin{array}{l}0 \\
0\end{array}$ & $\begin{array}{r}0,962 \\
0,97\end{array}$ & $\begin{array}{l}0 \\
0\end{array}$ & $\begin{array}{l}0,014 \\
0,015\end{array}$ \\
\hline TX & 0 & $\begin{array}{r}0-24 \\
25-60 \\
61-120\end{array}$ & $\begin{array}{c}0,9958 \\
0,9970 \\
0,9971\end{array}$ & $\begin{array}{l}0 \\
0 \\
0\end{array}$ & $\begin{array}{l}0 \\
0 \\
0\end{array}$ & $\begin{array}{l}0 \\
0 \\
0\end{array}$ & $\begin{array}{l}0 \\
0 \\
0\end{array}$ & $\begin{array}{r}0,0042 \\
0,003 \\
0,0029\end{array}$ \\
\hline
\end{tabular}

Tabella 1

Parametri di probabilità assunti nel modello di Markov per la coorte di pazienti trattati con calcio carbonato (terapia di riferimento): probabilità di trovarsi in emodialisi (HD) 0 in dialisi peritoneale (PD) all'inizio del trattamento e probabilità di transizione al termine di ogni ciclo mensile verso il proprio stato 0 verso altri stati collegati [45]

Legenda

HDc: complicazione in corso di emodialisi 0 emodiafiltrazione; PDC: complicazione in corso di dialisi pentoneale; TX: trapianto renale; D: morte. 


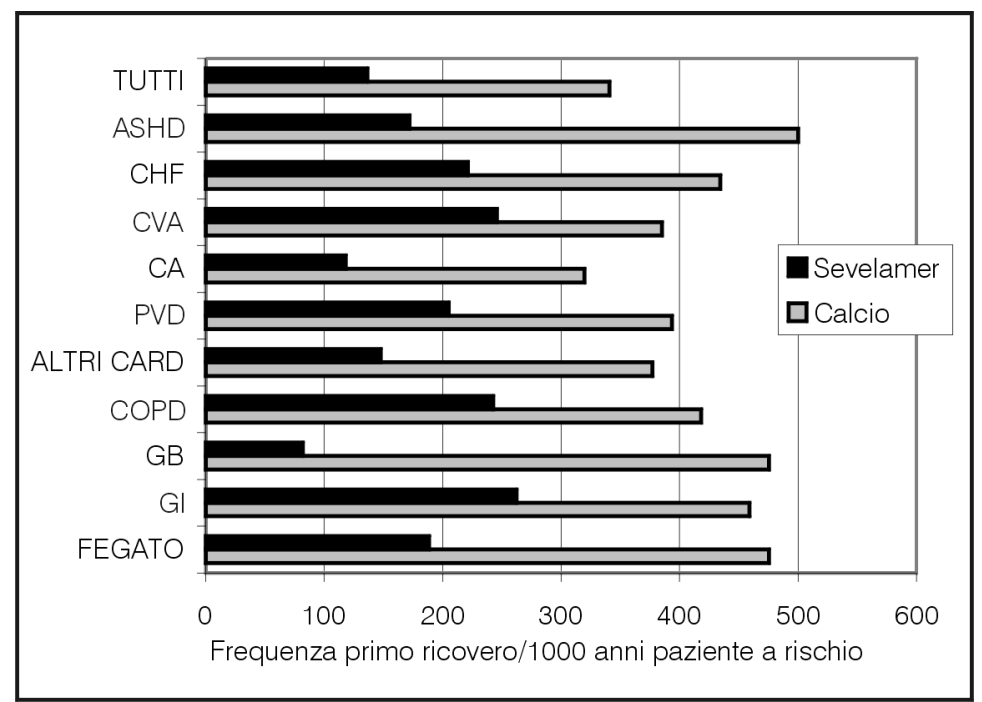

Figura 2

Incidenze di primo ricovero per complicanze in corso di emodialisi nei pazienti trattati con sevelamer in confronto con quelli trattati con sali di calcio (modificata da Collins et al, 2001 [41])

Legenda

ASHD: cardiopatia aterosclerotica; CHF: insufficienza cardiaca congestizia;

CVA: arteriopatia cerebrovascolare; CA: coronaropatia;

PVD: vasculopatia periferica; ALTRI CARD: altre cardiopatie;

COPD: bronco-pneumopatia cronica ostruttiva; GB: colecistopatia;

GI: gastropatia, sanguinamento gastrico; FEGATO: epatopatie.

\section{Parametri di efficacia}

Nell' analisi costo/efficacia l'efficacia è stata valutata come mesi di sopravvivenza (MOLS). Ovviamente i mesi di sopravvivenza nelle due coorti sono dovuti a molti fattori. Tuttavia nell' analisi costo/efficacia viene utilizzata l'efficacia incrementale che risulta adeguatamente rappresentata nel modello da noi proposto.

\section{Parametri di costo}

Nella stima dei costi abbiamo considerato essenzialmente i costi differenziali correlabili ai due trattamenti confrontati. Questa strategia permette di semplificare in qualche misura la stima dei costi, mantenendo intatta la potenzialità di valutare il costo incrementale che viene utilizzato nell' analisi costo/efficacia.

Abbiamo incluso esclusivamente i costi diretti sostenuti dal SSN italiano. Fatta eccezione per il costo del trasporto dei pazienti in dialisi presso centri ospedalieri o extra-ospedalieri, tutti gli altri costi sono costi diretti sanitari.

Ai fini della struttura markoviana del modello, abbiamo aggregato i costi in due tipologie: costo incrementale, relativo alle risorse consumate nella permanenza in uno degli stati previsti dal modello, e costo di transizione verso una delle complicazioni dell'emodialisi o della dialisi peritoneale o verso il trapianto renale.

Il costo incrementale è costituito dal costo mensile del farmaco sevelamer o calcio carbonato, dal costo mensile medio di una statina, dal costo mensile medio del trattamento dialitico. Abbiamo considerato tra $\mathrm{i}$ costi incrementali anche il costo del trattamento dialitico perché, sebbene sia un onere economico a carico del SSN comune a tutti i pazienti e comunque inevitabile, l'eventuale effetto incrementale di una terapia sulla mortalità comporta anche un incremento, apparentemente paradossale, del costo sanitario di gestione dei pazienti che sopravvivono più a lungo.

Il costo di transizione è costituito essenzialmente dal costo aggiuntivo di un ricovero per ognuna delle diverse complicanze considerate.

Nel costo dei farmaci abbiamo incluso solo il costo d'acquisto per il SSN, assumendo che il calcio carbonato e le statine siano distribuite nel $100 \%$ dei casi tramite farmacie del territorio e che il $60 \%$ di sevelamer sia dispensato tramite distribuzione diretta al prezzo di acquisto dell' ospedale. Il prezzo al pubblico è stato
Tabella 2

Posologie medie giornaliere, prezzi al pubblico e sconti applicati a favore del SSN per l'acquisto di sevelamer, calcio carbonato e statine

* Il prezzo d'acquisto del Renagel praticato all'ospedale $(164,54$ euro) è quello negoziato con il Ministero della Salute: viene calcolato sulla base del prezzo exfactory di 157,45 euro, applicando un ulteriore sconto del $5 \%$ ed aggiungendo al risultato il $10 \%$ di IVA. Pertanto, il prezzo d'acquisto ospedaliero di sevelamer comisponde al prezzo di vendita al pubblico scontato del $36,69 \%$

\begin{tabular}{|c|c|c|}
\hline Parametro di costo & Descrizione & Valore \\
\hline N_UN_METACALC & $\begin{array}{l}\text { Numero medio giornaliero di compresse di calcio carbonato } \\
\text { (Metocal) }\end{array}$ & 4,1 \\
\hline N_UN_REN & $\begin{array}{l}\text { Numero medio giornaliero di compresse di sevelamer } \\
\text { (Renagel 180) }\end{array}$ & 7,7 \\
\hline C_METOCAL & Prezzo confezione calcio carbonato (Metocal cpr 1250mg) & 8,99 euro \\
\hline C_REN180 & Prezzo confezione sevelamer (Renagel $180 \mathrm{cpr} 800 \mathrm{mg}$ ) & 259,86 euro \\
\hline SCONTO_CAL_SSN & $\begin{array}{l}\text { Sconto dovuto dalle farmacie al SSN sul calcio carbonato } \\
\text { (Metocal) }\end{array}$ & $5 \%$ \\
\hline SCONTO_REN_SSN & Sconto dovuto dalle farmacie al SSN sul sevelamer (Renagel) & $19 \%$ \\
\hline SCONTO_REN_HOSP & $\begin{array}{l}\text { Sconto minimo all'ospedale sul prezzo ex-factory di sevelamer } \\
\text { (Renagel)* }\end{array}$ & $5 \%$ \\
\hline FP_DISTDIR_REN & $\begin{array}{l}\text { Percentuale di distribuzione diretta del farmaco sevelamer sul } \\
\text { totale vendite }\end{array}$ & $60 \%$ \\
\hline C_DIE_STAT & Costo medio giornaliero della terapia con statine & 1,75 euro \\
\hline
\end{tabular}


scontato al SSN secondo le attuali normative. Nel calcolo della dose media giornaliera abbiamo considerato la distribuzione percentuale delle principali posologie dei singoli farmaci. La tabella 2 riporta le dosi medie giornaliere, $i$ prezzi al pubblico per confezione e gli sconti applicati a favore del SSN sul prezzo della confezione (o sul prezzo ex-factory per l' acquisto ospedaliero), scorporato dell'IVA.

Il costo medio giornaliero delle statine è stato calcolato su un mix dei prodotti attualmente in uso alle posologie giornaliere più frequenti. Il costo riportato in tabella 2 è relativo al prezzo al pubblico scontato del $5 \%$.

Non abbiamo considerato i costi delle reazioni avverse a sevelamer e al calcio, ritenendo che siano equivalenti. In quest' analisi non abbiamo altresì considerato i costi delle reazioni avverse alle statine.

Il costo mensile del trattamento dialitico è stato stimato in funzione del tipo di dialisi, delle relative tariffe, della frequenza delle sedute dialitiche, e della frequenza di utilizzo in Italia del- le diverse tecniche, secondo quanto risulta dal Registro Italiano della SIN. Il costo medio è stato stimato aggregando le tecniche di emodialisiemodiafiltrazione (HD) e le tecniche di dialisi peritoneale (PD). In tabella 3 sono riportati i valori delle tariffe assunte nel modello (relative alla Regione Piemonte) e le percentuali di utilizzo nell'ambito di ciascun raggruppamento.

Ai costi della dialisi sono stati aggiunti i costi relativi a esami e ad altre prestazioni integrative alla dialisi, che vengono tariffate a parte. Il tipo e la quantità di tali risorse rispecchia i protocolli assistenziali previsti dalle attuali linee guida italiane della SIN. Nella tabella 4 sono riportate le voci di costo e il relativo valore utilizzato nel modello.

La somma dei costi mensili di ciascun tipo di dialisi e dei relativi costi aggiuntivi, insieme alla frequenza di utilizzo di ciascuna tecnica, comporta una distribuzione dei costi mensili di trattamento dialitico relativamente ampia, di cui abbiamo tenuto conto nel modello. $\mathrm{La}$

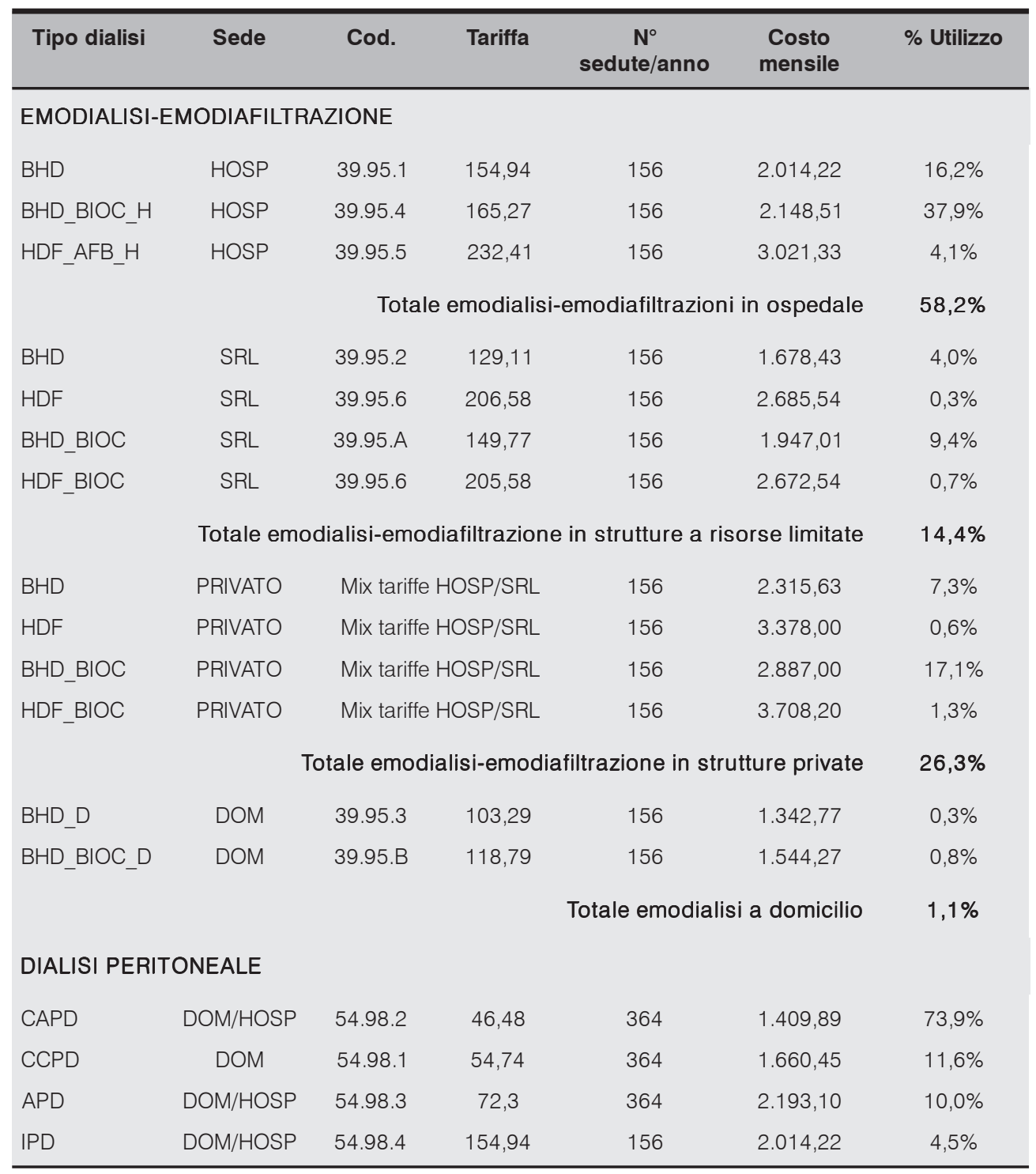

Tabella 3

Tariffe e costi mensili (in euro) dei diversi tipi di trattamento dialitico (adattato da: Registro SIN) 
Tabella 4

Tariffe e costi mensili (in euro) di prestazioni integrative del trattamento dialitico

\begin{tabular}{|c|c|c|c|c|c|c|}
\hline & & & & dialisi & Dialisi $P e$ & ritoneale \\
\hline & Cod. & Tariffa & No/anno & $\begin{array}{c}\text { Costo } \\
\text { mensile }\end{array}$ & $\mathrm{N}$ /anno & $\begin{array}{c}\text { Costo } \\
\text { mensile }\end{array}$ \\
\hline Fasciatura semplice & 93.56 .1 & 3,87 & 312 & 100,62 & ----- & ---- \\
\hline Medicazione & 96.59 & 3,87 & 156 & 50,31 & 12 & 3,87 \\
\hline Prelievo sangue venoso & 91.49 .2 & 2,58 & 66 & 14,19 & 12 & 2,58 \\
\hline Terapia infusionale & 99.25 .1 & 9,71 & 140 & 113,28 & ----- & ---- \\
\hline Somministrazione EPO & 99.23 & 9,71 & 78 & 63,12 & 78 & 63,12 \\
\hline Visita specialistica & 89.7 & 18,59 & 2 & 3,10 & 12 & 18,59 \\
\hline Stesura piano dialitico & 89.3 & 20,66 & 156 & 268,58 & 12 & 20,66 \\
\hline Irrigazione catetere venoso & 96.57 & 15,49 & 156 & 201,37 & ----- & ----- \\
\hline Ricircolo arterovenoso & 39.99 .1 & 17,46 & 4 & ----- & ----- & ----- \\
\hline Rev. catetere peritoneale & 97.29 .01 & 15,49 & ----- & ---- & 1 & 1,29 \\
\hline Esami ematochimici & Mix & & & 68,70 & & 68,70 \\
\hline Esami strumentali & Mix & & & 13,00 & & 13,00 \\
\hline Farmaci & Mix & & & 34,00 & & 34,00 \\
\hline Trasporto ambulanza/auto & Mix & & & $450,00 / 195,00$ & ----- & ----- \\
\hline
\end{tabular}

tabella 5 riporta i valori monetari dei costi incrementali mensili del trattamento dialitico con le rispettive probabilità relative, come assunte nel modello decisionale.

I costi di transizione sono stati calcolati in base al sistema tariffario DRG, ipotizzando che ogni caso di complicazione comporti un ricovero ordinario al quale corrisponde un esborso aggiuntivo da parte del SSN.

La tabella 6 riporta i valori monetari dei costi incrementali totali e dei costi di transizione imposti al modello. Tra i costi considerati vi è anche il costo di un trapianto e il costo mensile di assistenza sanitaria del paziente trapiantato, ipotizzando che il costo annuale di questi pazienti sia circa un decimo del costo iniziale del trapianto. Le tariffe utilizzate sono quelle deliberate dalla Regione Piemonte per il 2003. Tutti i costi sono valorizzati in unità monetarie euro al 2003.

\begin{tabular}{ccc}
\hline $\begin{array}{c}\text { Costo Incrementale } \\
\text { Mensile }\end{array}$ & $\begin{array}{c}\text { Distribuzione delle probabilità } \\
\text { di utilizzo nel paziente } \\
\text { non complicato }\end{array}$ & $\begin{array}{c}\text { Distribuzione delle probabilità } \\
\text { di utilizzo nel paziente ricoverato } \\
\text { per complicazioni }\end{array}$ \\
\hline Emodialisi & 0,003 & \\
2100 & 0,008 & \\
2301 & 0,040 & 0,279 \\
2435 & 0,094 & \\
2704 & 0,073 & 0,651 \\
2770 & 0,162 & \\
2950 & 0,171 & \\
2952 & 0,379 & \\
3085 & 0,007 & \\
3434 & 0,009 & 0,07 \\
3443 & 0,013 & 0,739 \\
3772 & 0,041 & 0,216 \\
3957 & & \\
\hline 1886 & 0,739 & \\
2240 & 0,096 & \\
2419 & 0,045 & \\
\hline Dialisi Peritoneale & 0,120 & \\
\hline 1636 & & \\
\hline
\end{tabular}

Tabella 5

Costi mensili globali

(in euro) del trattamento dialitico assunti nel modello e loro probabilità di utilizzo 


\section{Arco temporale}

La simulazione del modello è stata attuata assumendo l'arco temporale di 10 anni (120 cicli). Tale scelta è stata fatta per valorizzare compiutamente le differenze di outcome tra sevelamer e calcio carbonato, tenuto conto della sopravvivenza dei pazienti dializzati e assumendo che i benefici differenziali osservati dopo periodi di trattamento variabili da poche settimane a qualche mese si mantenessero stabili nel tempo.

\section{Tasso di sconto}

Considerato l'arco temporale della simulazione, abbiamo applicato un tasso di sconto costante del $5 \%$ annuo sui soli costi.

\section{Analisi di sensibilità}

È stata condotta un'approfondita analisi di sensibilità finalizzata a verificare la robustezza dei risultati ottenuti con il modello decisionale.

In particolare sono state effettuate numerose analisi di sensibilità ad una via sui parametri del modello definiti in modo incerto: il valore di questi singoli parametri è stato fatto variare entro range prestabiliti, verificando l'impatto di tale variazione sul rapporto costo/ efficacia incrementale.

Inoltre, è stata condotta un'analisi di sensibilità probabilistica utilizzando il metodo Monte Carlo per campionare le distribuzioni dei parametri e generare la simulazione di 1000

\begin{tabular}{|c|c|c|}
\hline C_T_ASHD & $\begin{array}{l}\text { DRG124 ricovero ordinario per complicazione da cardiopatia } \\
\text { aterosclerotica }\end{array}$ & 3731,71 \\
\hline C_T_CA & DRG121 ricovero ordinario per complicazione da coronaropatia & 5122,71 \\
\hline C_T_CHF & $\begin{array}{l}\text { DRG127 ricovero ordinario per complicazione da insufficienza } \\
\text { cardiaca congestizia }\end{array}$ & 3314,85 \\
\hline C_T_CO & DRG144 ricovero ordinario per complicazione da altre cardiopatie & 3755,64 \\
\hline C_T_COPD & $\begin{array}{l}\text { DRG88 ricovero ordinario per complicazione da } \\
\text { broncopneumopatia cronica ostruttiva }\end{array}$ & 2808,58 \\
\hline C_T_CVA & $\begin{array}{l}\text { DRG16 ricovero ordinario per complicazione da arteriopatia } \\
\text { cerebrovascolare }\end{array}$ & 3884,77 \\
\hline C_T_ES_ALTRE_HDC & $\begin{array}{l}\text { Costo esami aggiuntivi in caso di altre complicazioni da emodialisi } \\
\text { (HD) }\end{array}$ & 247,00 \\
\hline C_T_ES_ALTRE_PDC & $\begin{array}{l}\text { Costo esami aggiuntivi in caso di altre complicazioni da dialisi } \\
\text { peritoneale (PD) }\end{array}$ & 265,00 \\
\hline C_T_GB & DRG207 ricovero ordinario per complicazione da colecistopatia & 3249,63 \\
\hline C_T_Gl & $\begin{array}{l}\text { DRG174 ricovero ordinario per complicazione da gastropatia, } \\
\text { sanguinamento gastrico }\end{array}$ & 3844,53 \\
\hline C_T_LIV & DRG205 ricovero ordinario per complicazione da epatopatie & 3422,68 \\
\hline C_T_PVD & $\begin{array}{l}\text { DRG130 ricovero ordinario per complicazione da vasculopatia } \\
\text { periferica }\end{array}$ & 3427,68 \\
\hline C_T_RICDIAL & DRG317 ricovero ordinario per altre complicazione dialisi & 1966,98 \\
\hline TC_TX & Costo trapianto renale (DRG + Bonus) & 50090,00 \\
\hline C_INC_TX & Costo incrementale mensile di un paziente con trapianto renale & 501,00 \\
\hline C_MENS_CAL & Costo mensile acquisto calcio carbonato (Metocal) per il SSN & 17,53 \\
\hline C_MENS_REN & Costo mensile acquisto sevelamer (Renagel180) per il SSN & 236,24 \\
\hline C_INC_HD_CAL & $\begin{array}{l}\text { Costo incrementale mensile (dialisi, statina e calcio carbonato) per } \\
\text { paziente in emodialisi (HD) }\end{array}$ & 3038,63 \\
\hline C_INC_HDC_CAL & $\begin{array}{l}\text { Costo incrementale mensile (dialisi, statina e calcio carbonato) per } \\
\text { paziente in emodialisi (HD) complicata }\end{array}$ & 3150,32 \\
\hline C_INC_HD_REN & $\begin{array}{l}\text { Costo incrementale mensile (dialisi, statina e sevelamer) per } \\
\text { paziente in emodialisi (HD) }\end{array}$ & 3244,61 \\
\hline C_INC_HDC_REN & $\begin{array}{l}\text { Costo incrementale mensile (dialisi, statina e sevelamer) per } \\
\text { paziente in emodialisi (HD) complicata }\end{array}$ & 3356,30 \\
\hline C_INC_PD_CAL & $\begin{array}{l}\text { Costo incrementale mensile (dialisi, statina e calcio carbonato) per } \\
\text { paziente in dialisi peritoneale (PD) }\end{array}$ & 1823,08 \\
\hline C_INC_PDC_CAL & $\begin{array}{l}\text { Costo incrementale mensile (dialisi, statina e calcio carbonato) per } \\
\text { paziente in dialisi peritoneale (PD) complicata }\end{array}$ & 1874,25 \\
\hline C_INC_PD_REN & $\begin{array}{l}\text { Costo incrementale mensile (dialisi, statina e sevelamer) per } \\
\text { paziente in dialisi peritoneale (PD) }\end{array}$ & 2029,06 \\
\hline C_INC_PDC_REN & $\begin{array}{l}\text { Costo incrementale mensile (dialisi, statina e sevelamer) per } \\
\text { paziente in dialisi peritoneale (PD) complicata }\end{array}$ & 2080,23 \\
\hline V_DRG & Valore del punto DRG secondo la Regione Piemonte nel 2003 & 2630,00 \\
\hline
\end{tabular}

Tabella 6

Costi diretti sanitari (in euro) a carico del SSN imposti al modello decisionale come costi di transizione verso una delle complicazioni della dialisi o come costi incrementali mensili 
diversi casi. La distribuzione dei rapporti costo/efficacia incrementale stimati in tal modo è stata confrontata con il valore prefissato di Willingness-To Pay (WTP). Questo tipo di analisi è stata condotta assumendo come costo due diverse aggregazioni:

1) il costo totale netto di terapia, che includeva il costo di acquisto del sevelamer o del calcio carbonato, il costo delle statine e il costo delle complicazioni associate alla dialisi;

2) il costo totale di gestione del paziente dializzato, che includeva anche il costo di mantenimento in dialisi o in trattamento post-trapianto.

\section{Willingness-To-Pay}

Abbiamo assunto come riferimento i valori convenzionali ritenuti accettabili per una società industrializzata come quella italiana, ossia un valore $<=20.000$ euro per anno di vita guadagnato come "molto conveniente" e un valore compreso tra 20.000 euro e 50.000 euro come "conveniente". Nelle simulazioni del modello abbiamo impostato il valore di 4.000,00 euro/ MOLS (48.000,00 euro/YOLS) come limite massimo ritenuto accettabile per la società italiana.

\section{Software}

Il modello è stato implementato e analizzato mediante il software TreeAge Pro 4.2 (TreeAge Inc, USA).

\section{RISULTATI}

\section{Analisi base costo/efficacia}

La figura 3 rappresenta l'evoluzione temporale delle probabilità di trovarsi in uno dei 6 stati previsti dal modello di Markov per gli appartenenti alla coorte di pazienti trattati rispettivamente con sevelamer o con calcio carbonato. L'evoluzione delle probabilità è il risultato dell'insieme delle transizioni previste dal modello decisionale. Dall'analisi comparativa dei due riquadri di figura 3 risulta evidente come la mortalità sia il fattore dominante della dinamica complessiva del modello. La transizione verso il trapianto e la stessa insorgenza di complicazioni hanno un effetto limitato sulla struttura dinamica delle coorti di pazienti.

La figura 4 rappresenta le curve di sopravvivenza delle due coorti e conferma l'importanza della riduzione del rischio di mortalità correlata all'uso di sevelamer. Secondo i parametri del modello, dopo 10 anni di terapia con sevelamer la sopravvivenza sarebbe di circa il $40 \%$, una percentuale quasi raddoppiata rispetto a quella che oggi si prevede con l'uso di sali di calcio.

Questo risultato giustifica pienamente l'effettuazione dell'analisi costo/efficacia, laddove per efficacia si consideri il tempo medio di sopravvivenza nelle singole coorti e per efficacia incrementale, la differenza tra i valori medi di sopravvivenza da attribuire come beneficio al farmaco più efficace.

La tabella 7 riporta i risultati dell' analisi costo/efficacia effettuata con il modello decisionale sopra illustrato.

Assumendo che l'uso continuativo di sevelamer comporti una riduzione del rischio di mortalità del 44\% (RR=0,56 rispetto al calcio carbonato), il modello stima un guadagno medio di 18,8 mesi (un anno e mezzo circa) di vita nell'arco di dieci anni. Questo risultato viene raggiunto con un incremento della spesa farmaceutica di soli 663,19 euro per ogni mese di vita in più guadagnato.

Usare sevelamer al posto del calcio carbonato comporta un costo incrementale medio per acquisto farmaci di 12.489,05 euro in dieci anni. L'uso di sevelamer, tuttavia, induce anche significativi risparmi sul consumo di statine e sui ricoveri dovuti alle complicazioni in corso di dialisi. In dieci anni il risparmio medio stimato sul consumo di statine è di circa 400
Figura 3

Probabilità della popolazione di dializzati di trovarsi in uno dei 6 stati possibili previsti dal modello di Markov nei successivi stadi temporali (mesi)

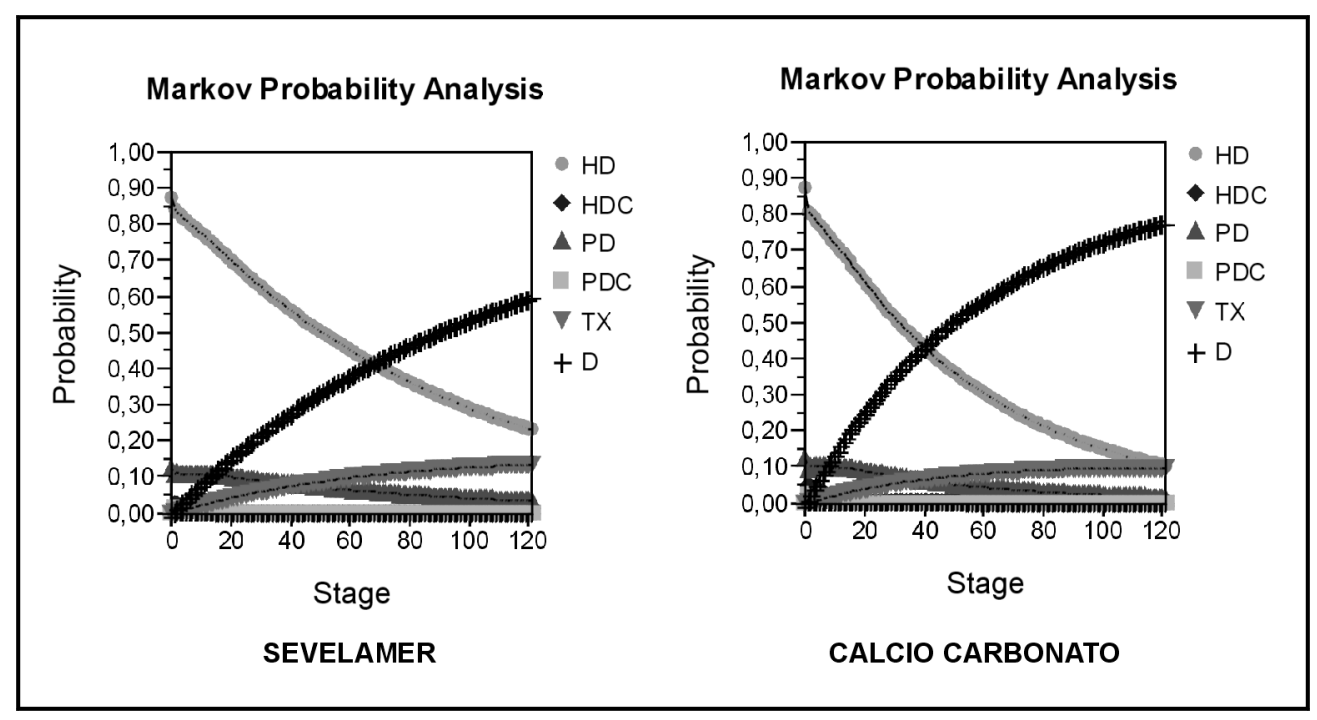


euro e il risparmio medio stimato sui ricoveri da complicazioni è di circa 550 euro. Questi risparmi riducono il costo incrementale di acquisto del sevelamer di circa 950 euro, portandolo a 11.544 euro in dieci anni. Pertanto l'incremento netto del costo totale di terapia, direttamente correlato al trattamento con sevelamer in alternativa al calcio carbonato, risulta essere di 613,05 euro/MOLS, ossia di circa 7.356 euro per ogni anno di vita guadagnato.

Questo valore del rapporto costo/efficacia incrementale (ICER) è nettamente inferiore al tetto massimo (fissato convenzionalmente in 20.000 euro) del costo che le società industrializzate ritengono molto conveniente e sicuramente accettabile per ottenere il guadagno di un anno di vita in più.

La riduzione della mortalità e il corrispettivo aumento della sopravvivenza dovuta all'uso di sevelamer comporta un incremento, apparentemente paradossale, dei costi sanitari sostenuti per attuare il trattamento dialitico. Il guadagno di 18,8 mesi di vita comporta, infatti, un incremento dei costi per dialisi a carico del SSN di circa 39.500 euro. Il conteggio di questo costo incrementale può apparire paradossale e improprio per due ordini di considerazioni: primo, il costo della dialisi è comunque un costo ineludibile ed indiscutibilmente a carico del SSN e, secondo, il guadagno di anni di vita è un valore etico prioritario che, secondo l'opinione di molti, non è scambiabile con un corrispettivo valore economico. Tuttavia, nella logica utilitaristica dell' analisi costo/efficacia, tutti i costi differenziali, direttamente o indirettamente correlati ai trattamenti confrontati, devono essere considerati e inclusi nel bilancio complessivo dei costi e dei risparmi per formare il costo incrementale net- to. D'altra parte l'approccio utilitaristico dell'analisi costo/efficacia si fonda su un criterio etico preciso che ritiene l'uso efficiente delle risorse un valore etico perché garantisce il maggior beneficio collettivo a parità di risorse disponibili. Nella fattispecie, non è in discussione il valore etico del guadagno di vita reso possibile dall'uso di sevelamer, ma questo incremento di sopravvivenza dei pazienti in dialisi, dovuto alla maggiore efficacia del farmaco, comporta un corrispettivo incremento di costi sanitari a carico del SSN che debbono essere considerati in applicazione del criterio economico della costo-opportunità.

Includendo, quindi, anche il costo aggiuntivo della dialisi, abbiamo stimato che, utilizzando sevelamer in sostituzione del cal-

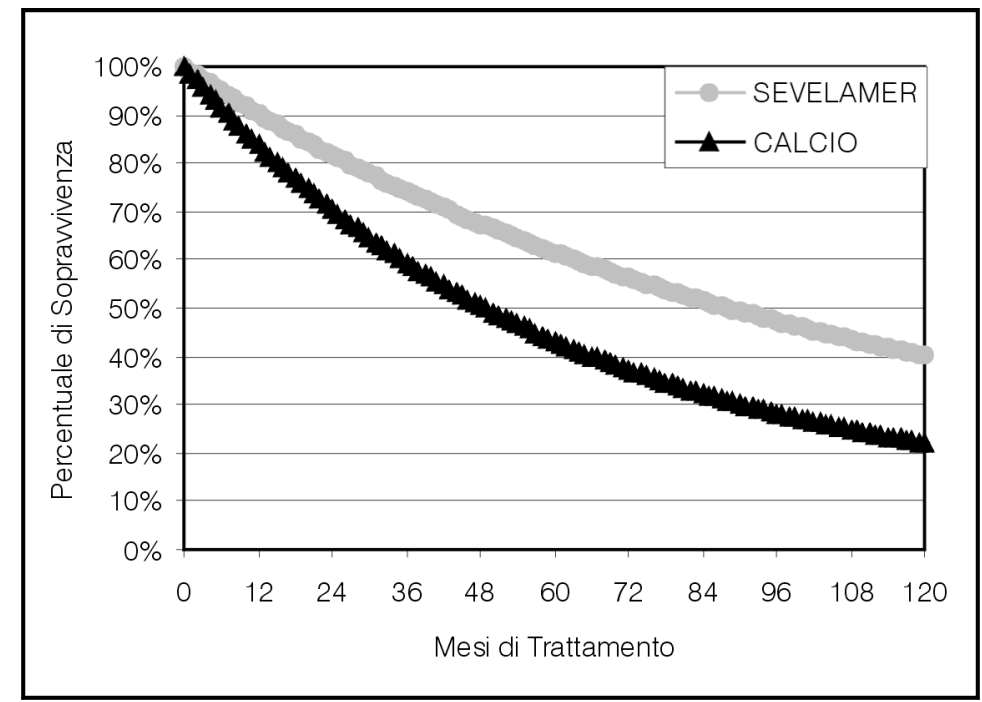

Figura 4

Curve di sopravvivenza delle popolazioni di dializzati trattati rispettivamente con sevelamer o con calcio carbonato nell'ipotesi base del modello che il rischio di mortalità con sevelamer sia pari al $56 \%$ del rischio di mortalità con calcio carbonato

\begin{tabular}{|c|c|c|c|c|c|c|c|}
\hline $\begin{array}{r}\text { Aggregazione } \\
\text { Costi }\end{array}$ & Strategia & $\begin{array}{r}\text { Costo } \\
\text { (in euro) }\end{array}$ & $\begin{array}{l}\Delta \text { Costo } \\
\text { (in euro) }\end{array}$ & $\begin{array}{r}\text { Efficacia } \\
\text { (MOLS) }\end{array}$ & $\begin{array}{r}\Delta \text { Efficacia } \\
\text { (MOLS) }\end{array}$ & $\begin{array}{r}\mathrm{C} / \mathrm{E} \\
\text { (euro/MOLS) }\end{array}$ & $\begin{array}{l}\Delta \mathrm{C} / \mathrm{E} \\
\text { (ICER) }\end{array}$ \\
\hline Costo Farmaci & $\begin{array}{r}\text { Calcio } \\
\text { Sevelamer }\end{array}$ & $\begin{array}{r}756,98 \\
13.246,04\end{array}$ & $12.489,05$ & $\begin{array}{l}59,0 \\
77,8\end{array}$ & 18,8 & $\begin{array}{r}12,83 \\
170,19\end{array}$ & 663,19 euro/MOLS \\
\hline Costo Statine & $\begin{array}{r}\text { Calcio } \\
\text { Sevelamer }\end{array}$ & $\begin{array}{r}1.054,70 \\
654,80\end{array}$ & - 399,90 & $\begin{array}{l}59,0 \\
77,8\end{array}$ & 18,8 & $\begin{array}{r}17,88 \\
8,41\end{array}$ & (Dominata) \\
\hline $\begin{array}{r}\text { Costo } \\
\text { Complicazioni }\end{array}$ & $\begin{array}{r}\text { Calcio } \\
\text { Sevelamer }\end{array}$ & $\begin{array}{r}1.471,31 \\
926,87\end{array}$ & $-544,44$ & $\begin{array}{l}59,0 \\
77,8\end{array}$ & 18,8 & $\begin{array}{r}24,94 \\
11,91\end{array}$ & (Dominata) \\
\hline $\begin{array}{l}\text { Costo Totale } \\
\text { Netto Terapia }\end{array}$ & $\begin{array}{r}\text { Calcio } \\
\text { Sevelamer }\end{array}$ & $\begin{array}{r}3.282,99 \\
14.827,71\end{array}$ & $11.544,71$ & $\begin{array}{l}59,0 \\
77,8\end{array}$ & 18,8 & $\begin{array}{r}55,64 \\
190,51\end{array}$ & 613,05 euro/MOLS \\
\hline $\begin{array}{r}\text { Costo dialisi e } \\
\text { trapianto }\end{array}$ & $\begin{array}{r}\text { Calcio } \\
\text { Sevelamer }\end{array}$ & $\begin{array}{l}132.293,62 \\
171.790,75\end{array}$ & $39.497,13$ & $\begin{array}{l}59,0 \\
77,8\end{array}$ & 18,8 & $\begin{array}{l}2.242,31 \\
2.207,24\end{array}$ & 2.097,37 euro/MOLS \\
\hline $\begin{array}{r}\text { Costo Totale } \\
\text { Gestione RRT }\end{array}$ & $\begin{array}{r}\text { Calcio } \\
\text { Sevelamer }\end{array}$ & $\begin{array}{c}135.576,61 \\
186.618,45\end{array}$ & $51.042,84$ & $\begin{array}{l}59,0 \\
77,8\end{array}$ & 18,8 & $\begin{array}{l}2.297,95 \\
2.397,75\end{array}$ & $2.710,42$ euro/MOLS \\
\hline
\end{tabular}

Tabella 7

Risultati dell'analisi costo/efficacia 
cio carbonato, il costo sanitario incrementale totale a carico del SSN è di 2.710,42 euro per ogni mese di vita guadagnato, ovvero di circa 32.525 euro per ogni anno aggiuntivo di sopravvivenza. Questo valore del rapporto costo/efficacia incrementale (ICER) rientra entro il range di valori (compreso convenzionalmente tra 20.000 euro e 50.000 euro) considerati ancora convenienti dalle società industrializzate a fronte di un anno di vita guadagnata.

\section{Analisi di sensibilità ad una via}

Le analisi di sensibilità ad una via indicano che i risultati della presente analisi costo/ efficacia dipendono principalmente dal grado di riduzione della mortalità nei pazienti dializzati trattati cronicamente con sevelamer in sostituzione del calcio carbonato. Infatti è l'efficacia incrementale del sevelamer sulla mortalità che consente di guadagnare mesi di vita. Qualora il tasso di mortalità associata al sevelamer fosse uguale o superiore al tasso di mortalità associata al calcio carbonato, l'efficacia incrementale sarebbe nulla e il costo incrementale del sevelamer, rispetto al calcio carbonato, costituirebbe un incremento netto dei costi sanitari non giustificato da un corrispettivo guadagno di vita. Nel caso in esame, invece, il tasso di mortalità associata al sevelamer è inferiore al tasso di mortalità associata al calcio carbonato, e pertanto si ottiene un guadagno di vita che aumenta in funzione dell'incremento di efficacia.

La figura 5 riporta il valore del rapporto costo/efficacia incrementale (ICER), riferito al costo totale di gestione, in funzione della variazione del rischio relativo di mortalità

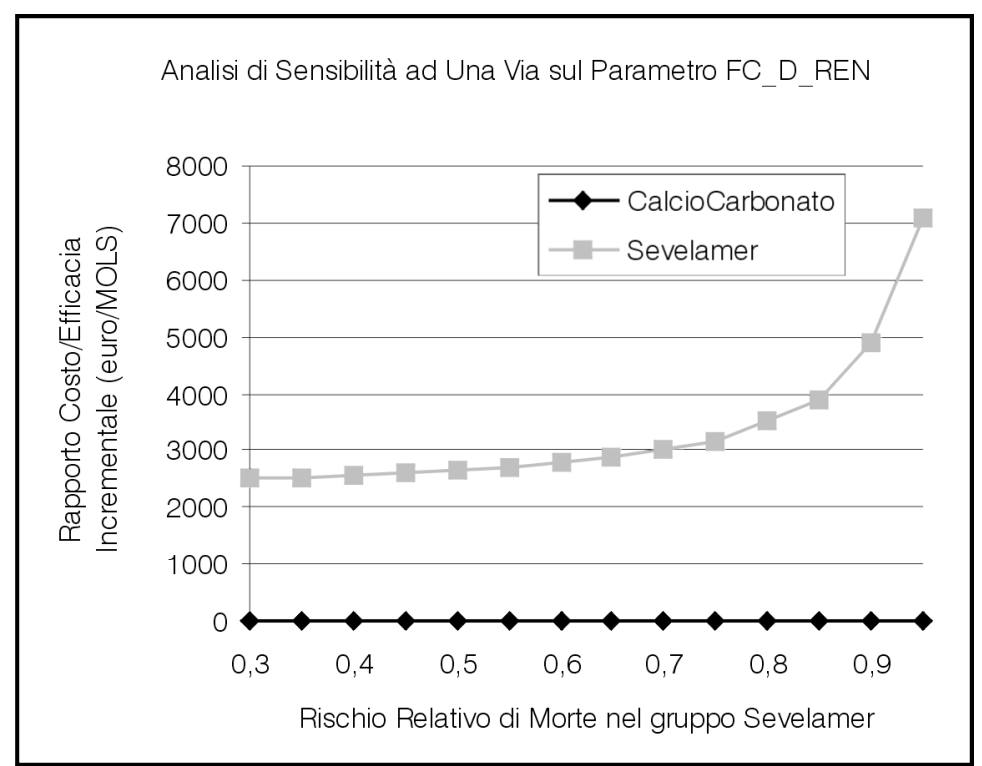

Figura 5

Analisi di sensibilità ad una via: variazione dell'effetto di sevelamer sulla riduzione percentuale della mortalità da dialisi. (FC_D_REN: Riduzione del rischio relativo di morte nel gruppo trattato con sevelamer. ICER: costo totale di gestione del paziente in dialisi/mesi di vita)
(FC_D_REN) nel range compreso tra 0,3 e 0,95. Il valore dell'ICER diminuisce rapidamente, con andamento quasi esponenziale, all'aumentare dell'effetto di sevelamer sulla riduzione del tasso di mortalità: la riduzione dell' ICER raggiunge un valore vicino al limite minimo quando la mortalità associata al sevelamer è inferiore del $20-25 \%$ rispetto a quella associata al calcio carbonato.

Il nostro modello di analisi costo/efficacia non è, invece, molto sensibile alle eventuali variazioni di altri parametri di efficacia del sevelamer, come la riduzione delle complicazioni da dialisi o la riduzione dell'uso di statine, che pure incidono positivamente sul consumo di risorse. Infatti, alla variazione di tali parametri non è direttamente associato un guadagno di vita, ma solo un sensibile risparmio di risorse sanitarie che riduce il costo netto di trattamento del sevelamer e il relativo costo incrementale netto.

Pertanto, l'analisi di sensibilità ad una via ha dimostrato che la variazione di tali parametri entro un range ragionevole comporta solo una modesta oscillazione del valore dell' ICER senza che venga modificato il giudizio di convenienza ottenuto con l'analisi di base. In particolare, la riduzione, nel range $0,4-1$, del rischio relativo di complicazioni da dialisi, ottenibile con l'uso di sevelamer in sostituzione del calcio carbonato, comporta solo una modesta variazione dell'ICER da 2.704 a 2.770 euro/MOLS, sebbene i risparmi sui ricoveri, in valore assoluto, siano rilevanti. Analogamente la variazione da 0 a 100 della percentuale di pazienti che evita l'uso di statine, adottando sevelamer al posto del calcio carbonato, comporta una variazione solo marginale del valore dell' ICER, da 2.710 a 2.748 euro/MOLS, sebbene l'entità assoluta del risparmio ottenibile con sevelamer sul consumo di statine non sia trascurabile.

La variazione del tasso di sconto annuale sui costi entro il range compreso tra 0 e $10 \%$, pur modificando sensibilmente il valore finale del rapporto costo/efficacia incrementale, non modifica il giudizio ottenuto con la simulazione dello scenario base, come dimostrano i risultati riportati nella tabella 8 .

La variazione della percentuale di distribuzione diretta del sevelamer entro il range estremo compreso tra 0 e $100 \%$ comporta modificazioni sensibili della spesa farmaceutica a carico del SSN, come riportato in tabella 9 , ma non modifica il giudizio ottenuto con la simulazione dello scenario base.

\section{Analisi di sensibilità probabilistica}

L'analisi di sensibilità probabilistica, attuata per valutare l'impatto della variabilità dei parametri attorno ai valori centrali, ha confermato le conclusioni ottenute sulla base del 
valore atteso stimato con la simulazione deterministica del modello base impostato sui valori medi.

Mediante la simulazione bidimensionale Monte Carlo sono stati simulati 1.000 casi, campionando ogni volta 100 punti dalle distribuzioni note e prefissate dei parametri nel modello. La simulazione origina 1.000 diverse soluzioni la cui distribuzione, opportunamente analizzata, fornisce ulteriori utili elementi per prendere adeguate decisioni. La simulazione è stata attuata due volte per studiare la distribuzione dei valori del rapporto costo/efficacia secondo due differenti tipologie di costo: il costo totale netto di terapia, che escludeva il costo della dialisi, ed il costo totale di gestione del paziente dializzato, che includeva anche il costo di mantenimento in dialisi.

La figura 6 riporta i risultati della simulazione Monte Carlo attuata assumendo il costo totale di gestione del paziente dializzato: sotto forma di scatterplot, sono rappresentati i rapporti costo/efficacia dei 1.000 casi simulati. Nell' area entro l'ellissi è concentrato il $95 \%$ dei casi. La totalità dei punti $(100 \%)$ è situata nel quadrante superiore destro (I) del diagramma decisionale costo/efficacia, che raggruppa le soluzioni dove ad un incremento dell'efficacia corrisponde un incremento dei costi. Ciò porta a concludere che vi è una elevatissima probabilità $(>99,99 \%)$ che il sevelamer sia maggiormente costo/efficace rispetto al calcio carbonato. Inoltre, la nube dei punti presenta una maggiore densità in un' area sottostante la retta diagonale tratteggiata che rappresenta la WTP, prefissata in 4.000,00 euro/MOLS: complessivamente il 98,2\% dei punti simulati è situato sotto, e solo lo $1,8 \%$ è situato sopra la retta WTP. Ciò dimostra in modo molto robusto che vi è una elevata probabilità che il valore del rapporto costo/efficacia incrementale del sevelamer, rispetto al

\begin{tabular}{rlrrrr}
\hline $\begin{array}{r}\text { Tasso } \\
\text { Sconto }\end{array}$ & Strategia & $\begin{array}{r}\text { Costi } \\
\text { (in euro) }\end{array}$ & $\begin{array}{r}\Delta \text { Costo } \\
\text { (in euro) }\end{array}$ & $\begin{array}{r}\text { C/E } \\
\text { (euro/MOLS) }\end{array}$ & $\begin{array}{r}\Delta \text { C/E } \\
\text { (ICER) }\end{array}$ \\
& & (euro/MOLS)
\end{tabular}

Tabella 8

Analisi di sensibilità ad una via: modificazione del risultato dell'analisi costo/efficacia,

condotta sul costo totale di gestione della RRT, al variare del tasso di sconto annuale sui costi

\begin{tabular}{|c|c|c|c|c|c|}
\hline Strategia & $\begin{array}{r}\% \\
\text { Distribuzione } \\
\text { Diretta } \\
\text { Sevelamer }\end{array}$ & $\begin{array}{r}\text { Costo medio } \\
\text { Acquisto } \\
\text { Sevelamer } \\
\text { (in euro) }\end{array}$ & $\begin{array}{l}\Delta \text { Costo } \\
\text { (in euro) }\end{array}$ & $\begin{array}{r}\text { Rapporto C/E } \\
\text { (euro/MOLS) }\end{array}$ & $\begin{array}{r}\Delta \mathrm{C} / \mathrm{E} \\
(\mathrm{ICER}) \\
\text { (euro/MOLS) }\end{array}$ \\
\hline \multirow[t]{6}{*}{ Calcio } & $0 \%$ & 756,98 & & 12,93 & \\
\hline & $0 \%$ & $15.160,85$ & $14.403,87$ & 194,79 & 764,87 \\
\hline & $10 \%$ & $14.841,72$ & $14.084,73$ & 190,69 & 747,93 \\
\hline & $20 \%$ & $14.522,58$ & $13.765,60$ & 186,59 & 730,98 \\
\hline & $30 \%$ & $14.203,44$ & $13.446,46$ & 182,49 & 714,03 \\
\hline & $40 \%$ & $13.884,31$ & $13.127,33$ & 178,39 & 697,09 \\
\hline \multirow[t]{6}{*}{ Sevelamer } & $50 \%$ & $13.565,17$ & $12.808,19$ & 174,29 & 680,14 \\
\hline & $60 \%$ & $13.246,04$ & $12.489,05$ & 170,19 & 663,19 \\
\hline & $70 \%$ & $12.926,90$ & $12.169,92$ & 166,09 & 646,25 \\
\hline & $80 \%$ & $12.607,76$ & $11.850,78$ & 161,99 & 629,30 \\
\hline & $90 \%$ & $12.288,63$ & $11.531,65$ & 157,89 & 612,35 \\
\hline & $100 \%$ & $11.969,49$ & $11.212,51$ & 153,79 & 595,40 \\
\hline
\end{tabular}

\section{Tabella 9}

Analisi di sensibilità ad una via: modificazione del risultato dell'analisi costo/efficacia, condotta considerando il solo costo d'acquisto medio di sevelamer, al variare della percentuale di distribuzione diretta del farmaco 
calcio carbonato, rientri entro il range di valori considerati convenienti dai paesi industrializzati a fronte del guadagno di un mese di vita. Risultati analoghi, ma ancora più favorevoli, sono stati ottenuti con la simulazione Monte Carlo impostata sul costo totale netto di terapia, nettamente inferiore al costo totale di gestione del paziente dializzato.

\section{DISCUSSIONE}

L'elevato costo di acquisto del sevelamer è l'unico consistente inconveniente che ne ostacola l'utilizzo su vasta scala nel trattamento dell'iperfosforemia dei pazienti dializzati.

Recenti ricerche cliniche controllate hanno dimostrato che l'uso cronico di sevelamer a dosi adeguate è in grado non solo di con-

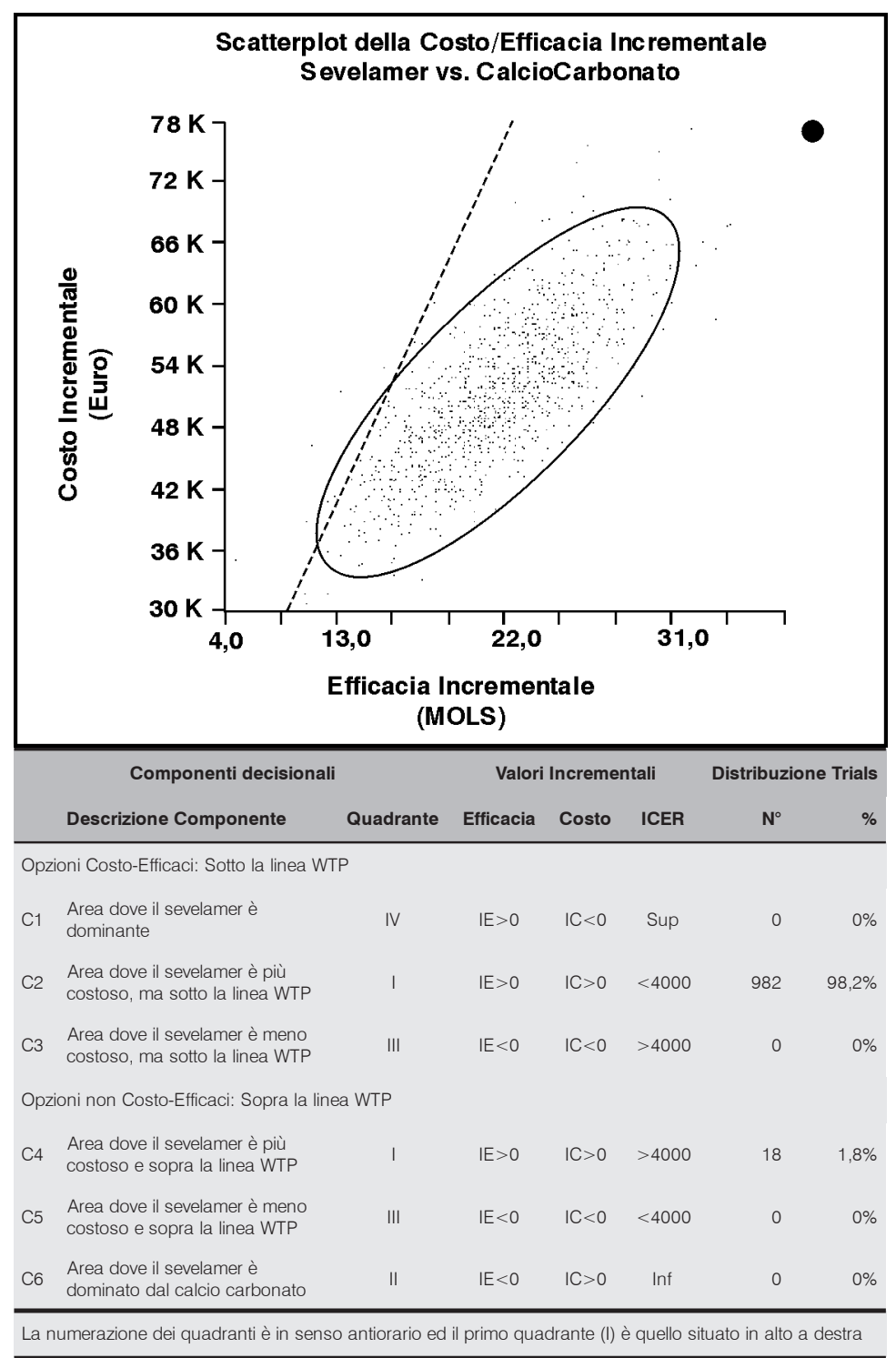

Figura 6

Analisi di sensibilità probabilistica: scatterplot della costo/efficacia incrementale dei 1.000 casi simulati mediante metodo Monte Carlo, assumendo il costo totale di gestione del paziente dializzato. Nel sottostante inserto la distribuzione dei punti viene analizzata, in chiave decisionale, in riferimento alla linea diagonale tratteggiata che rappresenta il valore WTP, fissato in 4.000,00 euro/MOLS trollare l'eccessivo accumulo di fosforo e di ridurre i livelli del paratormone, ma anche di prevenire o far regredire la calcificazione dei tessuti extraossei, in particolare a livello del sistema cardiovascolare, con la conseguente riduzione del rischio di complicanze e di mortalità correlate all'insufficienza renale cronica e al trattamento dialitico.

La riduzione del rischio di complicanze è un effetto del sevelamer ormai accertato con prove robuste, comprovate da significatività statistica [41].

Esistono altresì prove cliniche convincenti sulla efficacia del trattamento a lungo termine con sevelamer nel ridurre il rischio di mortalità, soprattutto cardiovascolare. Secondo alcune stime la riduzione del rischio di mortalità è superiore al 40\%; secondo altre stime, più conservative, si attesta attorno al 30\% [40, 41]. Una conferma definitiva dell'efficacia del sevelamer nel ridurre il rischio di mortalità cardiovascolare è attesa dalla conclusione, ormai prossima, dello studio D-COR, implementato appositamente per questo scopo.

Abbiamo effettuato il presente studio per verificare la convenienza ad utilizzare sevelamer, in sostituzione del meno costoso calcio carbonato, nella prospettiva del SSN italiano. In particolare la nostra valutazione ha inteso verificare se la riduzione del rischio di complicazioni e di mortalità possa giustificare l'incremento della spesa farmaceutica associata all'uso di sevelamer.

Abbiamo condotto questo studio farmacoeconomico implementando un apposito modello decisionale costo/efficacia, caratterizzato da una struttura mista: il problema decisionale fondamentale, quello della scelta dell'alternativa più conveniente per il SSN tra sevelamer e calcio carbonato, viene rappresentato con un classico albero decisionale; le due diramazioni che partono dalla radice dell'albero terminano con un nodo markoviano mediante il quale viene rappresentata l'evoluzione nel tempo degli stati di malattia e gli effetti differenziali dei due farmaci.

L'adozione della tecnica di analisi costo/ efficacia parte dall'ipotesi che il sevelamer possa comportare un guadagno in termini di sopravvivenza. Coerentemente con questo assunto, abbiamo considerato come parametro di efficacia i mesi di vita guadagnati.

Il modello è stato alimentato con parametri di probabilità desunti in gran parte dalla letteratura e solo in minima parte da noi stimati ex novo sulla base di evidenze disponibili in letteratura o nel Registro Nazionale Dialisi gestito dalla SIN [45].

I parametri di costo sono stati stimati ricostruendo con un panel di nefrologi il profilo qualitativo e quantitativo delle risorse sanita- 
rie consumate per effettuare il trattamento farmacologico in esame e per gestire le conseguenze che possono derivare da una loro efficacia differenziale. In particolare, poiché il sevelamer comporta una minore incidenza di complicanze e di ricoveri ad esse correlate ed una significativa riduzione dei livelli di LDLcolesterolo, abbiamo considerato le risorse che il SSN deve impiegare per gestire le complicanze associate al trattamento dialitico e per trattare le dislipidemie. La sommatoria dei costi di acquisto di sevelamer o calcio carbonato, del costo delle statine e del costo delle complicazioni associate alla dialisi, rappresentata come costo totale netto di terapia, ha costituito l'aggregazione base dei costi della nostra analisi farmacoeconomica. Parallelamente, poiché il modello assume come ipotesi principale che il sevelamer riduca la mortalità e quindi induca un guadagno di mesi di vita, abbiamo stimato anche il costo totale di gestione del paziente in dialisi come ulteriore tipo di costo aggregato da rapportare all'efficacia dei due farmaci. Questo costo include anche il costo della dialisi e del mantenimento del paziente trapiantato, in aggiunta al costo netto di terapia. Questa scelta è giustificata e razionale dal momento che l'eventuale guadagno di mesi di vita, indotto dal farmaco più efficace, comporta inevitabilmente un significativo incremento dei costi sanitari dovuti alla necessità di mantenere questi pazienti in dialisi $\mathrm{o}$ in trattamento post-trapianto per un periodo di tempo più lungo, come conseguenza diretta dell'incremento di efficacia. L'analisi costo/efficacia ha come scopo dichiarato quello di indicare l'alternativa più conveniente per il decisore, ossia l'alternativa che garantisce la migliore efficienza allocativa delle scarse risorse disponibili. Le soluzioni prospettate dall'analisi costo/efficacia soddisfano il criterio etico del raggiungimento del massimo beneficio sanitario collettivo ottenibile con le risorse disponibili, ma tale soluzione può risultare conflittuale con altri criteri etici e soprattutto con altre impostazioni etiche che privilegiano la centralità e il valore della vita delle singole persone, trascurando o ignorando il valore etico implicito anche nel criterio economico della costo-opportunità.

Le risorse consumate sono state valorizzate in unità monetarie (euro) assumendo come riferimento le tariffe delle prestazioni in vigore durante il 2003 nella Regione Piemonte, tariffe che sono comunque rappresentative per l'intera nazione.

Il modello decisionale è stato quindi simulato secondo uno scenario base e, successivamente, sottoposto ad esaustive analisi di sensibilità per verificare la robustezza delle conclusioni.
Lo scenario base ipotizza che l'uso prolungato di sevelamer, in confronto con il calcio carbonato, possa ridurre del $44 \%$ la mortalità e del 54\% l'insieme delle complicanze della dialisi. L'analisi costo/efficacia incrementale indica che il sevelamer è maggiormente costo/efficace e che il costo aggiuntivo che il SSN deve sostenere per un mese di vita in più guadagnato (circa 613 euro, se si considera il costo netto di terapia, e circa 2.710 euro, se si considera il costo totale di gestione del paziente dializzato) è inferiore al valore di WTP convenzionalmente ritenuto molto conveniente o conveniente dai paesi industrializzati.

L'uso di sevelamer comporta risparmi sensibili sul consumo di statine e sui ricoveri indotti dalle complicanze. Tali risparmi, tuttavia, sebbene significativi in valore assoluto, non annullano l'incremento dei costi correlato all'uso di sevelamer. La riduzione del rischio di complicanze, pur essendo percentualmente elevata, è molto bassa in termini assoluti e pertanto incide solo marginalmente sul bilancio economico finale. In altri termini occorre trattare un numero elevato di pazienti per ottenere la prevenzione delle complicazioni in un soggetto dializzato ed il costo del farmaco non viene controbilanciato dai risparmi sulle complicazioni. Analoga considerazione si può fare per l'uso delle statine.

L'effetto sulla mortalità del sevelamer è il parametro critico che controlla il risultato dell'analisi costo/efficacia e quindi indirizza la decisione. Si deve, tuttavia, notare come sia sufficiente una modesta riduzione percentuale della mortalità per rendere accettabile l'uso di sevelamer. Una riduzione del $20 \%$ della mortalità riporta il valore del rapporto costo/efficacia incrementale sotto il limite della WTP. Una riduzione del $30 \%$ comporta un risultato quasi massimale: ulteriori riduzioni della mortalità migliorano solo di poco il valore del rapporto costo/efficacia incrementale.

I dati clinici attualmente disponibili indicano che l'uso prolungato di sevelamer può ridurre di almeno il 30\% il rischio di mortalità $[40,41]$, rendendo quindi ampiamente valido il modello da noi proposto.

I risultati ottenuti calcolando deterministicamente il valore atteso dell'ICER sono stati confermati dalle analisi di sensibilità probabilistica, attuate mediante la simulazione col metodo Monte Carlo. Inoltre una estensiva analisi di sensibilità ad una via, attuata sui parametri del modello definiti con maggiore incertezza, ha confermato le decisioni proposte dall' analisi principale. Pertanto, i risultati sopra illustrati e le indicazioni decisionali derivabili devono essere considerati robusti. 
L'evidenza che l'uso di sevelamer comporta benefici rilevanti sulla mortalità e sulla morbilità dei pazienti dializzati deve pesare anche in termini etici, e non solo economici, nel comporre il giudizio finale di accettabilità da parte del SSN e della società italiana. D'altra parte, il costo della dialisi, sebbene elevato, è accettato da tutte le nazioni industrializzate e, anzi, è divenuto per molti lo standard di riferi- mento come valore massimo che la società è disposta a pagare per ottenere un anno di vita in più.

La presente analisi ha dimostrato che l'uso di sevelamer, oltre a prolungare significativamente la vita dei pazienti dializzati, induce costi incrementali che sono accettabili per il nostro SSN, perché il rapporto costo/efficacia incrementale risulta inferiore alla WTP.

\section{BIBLIOGRAFIA}

1. Delmez JA, Slatopolsky E. Hyperphosphatemia: its consequences and treatment in patients with chronic renal disease. Am J Kidney Dis 19: 3003-317, 1992.

2. Llach F. Hyperphosphatemia in end-stage renal disease patients: pathophysiological consequences. Kidney Int 56: S31-S37, 1999.

3. London GM. Cardiovascular calcifications in uremic patients: clinical impact on cardiovascular function. J Am Soc Nephrol 14: S305-S309, 2003.

4. Block GA, Hulbert-Shearon TE, Levin NW, et al. Association of serum phosphorus and calcium x phosphate product with mortality risk in chronic hemodialysis patients: a national study. Am J Kidney Dis 31: 607-617, 1998.

5. Guerin AAP, London GM, Marchais SJ, et al. Arterial stiffening and vascular calcifications in end-stage renal disease. Nephrol Dial Transplant 15: 1014-1021, 2000.

6. Blacher J, Guerin AP, Pannier B, et al. Arterial calcifications, arterial stiffness, and cardiovascular risk in endstage renal disease. Hypertension 38: 938-942, 2001.

7. Raggi P, Boulay A, Chasan-Taber S, et al. Cardiac calcification in adult hemodialysis patients: a link between end-stage renal disease and cardiovascular disease? J Am Coll Cardiol 39: 695-701, 2002.

8. US Renal Data System 1998. USRDS 1998 Annual Data Report. Bethesda, Maryland, National Institute of Health, National Institute of Diabetes and Digestive and Kidney Diseases.

9. Maillaux LU, Haley WE. Hypertension in the ESRD patient: pathophysiology, therapy, outcomes, and future directions. Am J Kidney Dis 32: 705-719, 1998.

10. Owen WF, Madore F, Brenner BM. An observational study of cardiovascular characteristics of long-term endstage renal disease survivors. Am J Kidney Dis 28: 931-936, 1996.

11. DeFronzo RA. Pathogenesis of glucose intolerance in uremia. Metabolism 27: 1866-80, 1978.

12. Boston AG, Shemin D, Lapane KL, et al. Hyperomocysteinemia, hyperfibrinogemia, and lipoprotein (a) excess in maintenance dialysis patients: a matched case-control study. Atherosclerosis 125:91-101, 1996.

13. Avram MM, Goldwasser P, Burrell DE, et al. The uremic dyslipidemia: a cross-sectional and longitudinal study. Am J Kidney Dis 20: 324-335, 1992.

14. Wanner C, Zimmermann J,Schwedler S, et al. Inflammation and cardiovascular risk in dialysis patients. Kidney Int 61: S99-S102, 2002.

15. Ikizler TA, Wingard RL, Harvell J, et al. Association of morbidity with markers of nutrition and inflammation in chronic hemodialysis patients: a prospective study. Kidney Int 55: 1945-1951, 1999 
16. Brancaccio D, Tetta C, Gallieni M et al. Inflammation, CRP, calcium overload and a high calcium-phosphate product: 'a liaison dangereuse'. Nephrol Dial Transplant 17: 201-203, 2002

17. Prichard SS. Impact of dyslipidemia in end-stage renal disease. J Am Soc Nephrol 14: S315-S320, 2003.

18. Drueke TB. Genesis of atherosclerosis in uremic patients. Mineral and Electrolyte Metabolism 25: 251-257, 1999.

19. Lowrie EG, Lew NL. Death risk in hemodialysis patients: the predictive value of commonly measured variables and an evaluation of death rate differences between facilities. Am J Kidney Dis 15: 458-482, 1990.

20. Ketteler M, Wanner C, Metzger T, et al. Deficiencies of calcium-regulatory proteins in dialysis patients: a novel concept of cardiovascular calcification in uremia. Kidney Int 84 (Suppl):S84-7, 2003.

21. Hou SH, Zhao J, Ellman CF, et al. Calcium and phosphorus fluxes during hemodialysis with low calcium dialysate. Am J Kidney Dis 18: 217-224, 1991.

22. Hergesell O, Ritz E. Phosphate binders in uraemia: pharmacodynamics, pharmacoeconomics, pharmacoethics. Nephrol Dial Transplant 17: 14-17, 2002.

23. Malluche HH, Mawad H. Management of hyperphosphatemia of chronic kidney disease: lessons from the past and future directions. Nephrol Dial Transplant 1/: 1170-1175, 2002.

24. Bleyer AJ. Phosphate binder usage in kidney failure patients. Expert Opin Pharmacother 4: 941-947, 2003.

25. Kuzela DC, Huffer WE, Conger JD, et al. Soft tissue calcification in chronic dialysis patients. Am J Pathol 86:403-424, 1977.

26. Sperschneider H, Gunther K, Marzoll I, et al. Calcium carbonate: an efficient and safe phosphate binder in hemodialysis patients? A 3-year study. Nephrol Dial Transplant 8: 530-534, 1993.

27. Kurz P, Monier-Faugere MC, Bognar B, et al. Evidence for abnormal calcium homeostasis in patients with adynamic bone disease. Kidney Int 46: 855-861, 1994.

28. Hsu CH. Are we mismanaging calcium and phosphate metabolism in renal failure. Am J Kidney Dis 29: 641-649, 1997.

29. Goodman WG, Goldin J, Kuizon BD, et al. Coronary-artery calcification in young adults with end-stage renal disease who are undergoing dialysis. N Eng J Med 342: 1478-1483, 2000.

30. Bleyer AJ, Burke SK, Dillon M. et al. A comparison of the calcium-free phosphate binder sevelamer hydrochloride with calcium acetate in the treatment of hyperphosphatemia in hemodialysis patients. Am J Kidney Dis 33: 694-701, 1999.

31. Slatopolsky EA, Burke SK, Dillon MA, et al The Renagel Study Group. RenaGel, a non-absorbed calcium-and aluminium-free phosphate binder, lowers serum phosphorus and parathyroid hormone. Kidney Int 55: 299-307, 1999.

32. Hervas JG, Prados D, Cerezo S. Treatment of hyperphosphatemia with sevelamer hydrochloride in hemodialysis patients: a comparison with calcium acetate. Kidney Int 85: S69-S72, 2003.

33. Ortiz A, Rios F, Melero R, et al. Experience with sevelamer in peritoneal dialysis. Nefrologia 23: 432-436, 2003.

34. Chertow GM, Burker SK, Raggi P. Sevelamer attenuates the progression of coronary and aortic calcification in hemodialysis patients. Kidney Int. 62: 245-252, 2002.

35. Chertow GM, Raggi P, McCarthy JT, et al. The effects of sevelamer and calcium acetate on proxies of atherosclerotic and arteriosclerotic vascular disease in hemodialysis patients. Am J Nephrol 23: 301-314, 2003.

36. Chertow GM. Slowing the progression of vascular calcification in hemodialysis. J Am Soc Nephrol 14: S310-S314, 2003.

37. Burke SK, Dillon MA, Hemken DE, et al. Meta-analysis of the effect of sevelamer on phosphorus, calcium, PTH, and serum lipids in dialysis patients. Adv Ren Replac Ther 10: 133-145, 2003.

38. Wilkes BM, Reiner D, Kern M, et al. Simultaneous lowering of serum phosphate and LDL-cholesterol by sevelamer hydrochloride (RenaGel) in dialysis patients. Clin Nephrol 50: 381-386, 1998.

39. Chertow GM, Burke SK, Dillon MA, et al. Long-term effects of sevelamer hydrochloride on the calcium x phosphate product and lipid profile of hemodialysis patients. Nephrol Dial Transplant 14: 2907-2914, 1999. 
40. Walters BA, Delahunty MI, Nabut JL, et al. Reduction in cardiac mortality in hemodialysis patients on sevelamer hydrochloride compared with phosphate binders containing calcium. J Am Soc Nephrol 13: 596A, 2002.

41. Collins AJ, St.Peter WL, Dalleska FW, et al. Hospitalization risks between Renagel phosphate binder treated and non-Renagel treated patients. Clin Nephrol 54: 334-241, 2000.

42. McIntyre CW, Patel V, Taylor GS, et al. A prospective study of combination therapy for hyperphosphatemia with calcium-containing phosphate binders and sevelamer in hypercalcaemic haemodalysis patients. Nephrol Dial Transplant 17: 1643-1648, 2002.

43. Sadek T, Mazouz H, Bahloul H, et al. Sevelamer hydrochloride with or without alphacalcidol or higher dialysate calcium vs calcium carbonate in dialysis patients: an open-label, randomized study. Nephrol Dial Transplant 18: 582-589, 2003.

44. Burke S, Amin N, Incerti C, et al. Sevelamer hydrochloride (Renagel), a nonabsorbed phosphate-binding polymer, does not interfere with digoxin or warfarin pharmacokinetics. J Clin Pharmacol 41: 193-198, 2001.

45. Kirby L, Vale L. Dialysis for end-stage renal disease: determining cost-effective approach. Int J Technol Ass Health Care 17: 181-189, 2001. 